\title{
FACTORS AFFECTING SEASONING OF TIMBER USING SAWDUST OPERATED
} KILN

\author{
P. L. A. M. C. Wijewarnasuriya and H. S. Amarasekera \\ Department of Forestry and Environmental Science, University of Sri Jayewardenepura. Sri Lanka \\ *azankamn@gmail.com, Tel-+ 94779449873
}

\begin{abstract}
This study was carried out to investigate the applicability of sawdust operated kiln developed by Senadheera (2009), by investigating the factors affecting its operation such as burner and cost efficiencies.Most efficient sawdust feeding rate for the burner was found to be $60 \mathrm{~g} \mathrm{~min}^{-1}$ having particle diameter greater than $1 \mathrm{~mm}$. Kiln was tested by seasoning Rubber (Hevea brasiliensis), Mahogany (Swietenia macrophylla), Lunumidella (Melia dubia) and Albizia (Paraserianthes falcataria). Albizia showed the highest drying rate, followed by Rubber, Lunumidella and Mahogany. This sawdust operated kiln consumed 144 hours to dry 25 $\mathrm{ft}^{3}$ of $25 \mathrm{~mm}$ thick rubber wood from green conditions to $13 \%$ of moisture content. The sawdust operated kiln in the present study showed the lowest cost efficiency compared with two other industrially operating kilns in the country. The highest cost efficiency was observed in the kiln at Rowood Lanka Pvt Ltd. However, according to cost - benefit analysis carried out for three kilns, kiln at State Timber Corporation showed its ability for a long run enterprise. Each kiln contributed approximately $25 \%$ of cost on energy out of total seasoning cost. Cost of seasoning per unit volume of timber and cost of seasoning per unit volume of timber per unit time for this kiln was 1.7 and 2.5 fold higher than that of kiln at Rowood Lanka Pvt Ltd respectively. It was found that sawdust operated kiln in the present study will not be sustained as an enterprise due to higher cost of seasoning.
\end{abstract}

Key words: kiln seasoning, sawdust, sawdust operated kiln, drying rate, cost efficiency, cost benefit analysis

\section{INTRODUCTION}

Seasoning of timber always possesses a cost due requirement of energy for the generation of heat. Use of petroleum and electricity for the heat generation is very expensive which is not affordable to small and medium scale saw millers. Therefore, most of kilns in Sri Lanka do not possess kiln seasoning facilities. On the other hand, saw milling industry generates a fair amount of sawdust as waste. A large amount of sawdust is disposed as a solid waste as its ultimate fate. A study done in Western Province of Sri Lanka has revealed that approximately $56 \%$ of wood is wasted as sawdust and wood particles (Weerawansa, 1997). Approximately 18\% of kilns in Sri Lanka utilise sawdust in order to generate heat required for seasoning (Senadheera, 2009). These two facts confirm that there is a potential to utilise sawdust as an energy source for kiln seasoning of timber in Sri Lanka. Therefore, developing a better and cost efficient technique to convert sawdust into heat is a requirement. Sawdust is cheaply available in bulk quantities; it will be a better option for small and medium scale saw millers. In 2009, D.K.L.K. Senadheera developed a prototype sawdust burner in order to utilise sawdust for the kiln seasoning of timber. This prototype sawdust burner has been coupled to a kiln chamber situated in University of Sri Jayewardenepura. In this study, an attempt is made to increase the efficiency of this sawdust burner for kiln seasoning.

The main aim of this study is to investigate the applicability of this sawdust operated kiln for the seasoning of timber by investigating the factors affecting its operation such as burner efficiency and cost. 


\section{MATERIALS AND METHODS}

\subsection{INVESTIGATION OF THE PERFORMANCE OF SAWDUST OPERATED KILN}

Sawdust operated burner was tested for investigating its maximum efficiency for sawdust particle size and feeding rate (a mass of sawdust per minute). Using a mesh which has a pore diameter of $1 \mathrm{~mm}$, sawdust was separated into two parts. Those two sawdust types were burnt one at a time under a certain sawdust feeding rate. Heat generated from burner by combusting sawdust was directed to heat a beaker containing a known mass of water under a certain period of time. As water was heating its temperature was measured and recorded at regular intervals. Same procedure was followed in investigating effective sawdust feeding rate (a mass of sawdust per minute) for the burner. Exhaust pipe (which contains heated air) coming from the burner, has been arranged as a spiral in the kiln chamber close to the walls of the chamber in the earlier design (Senadheera, 2009). The material of the pipe was iron which has a thermal conductivity coefficient value of 80 $\mathrm{W} \mathrm{m}{ }^{-1}{ }^{\circ} \mathrm{C}^{-1}$. In the present study that pipe was replaced by an aluminium pipe and it was arranged close to one wall of the chamber. Aluminium possesses relatively a higher coefficient of thermal conductivity, which is $250 \mathrm{~W} \mathrm{~m}^{-1} \mathrm{C}^{-1}$.

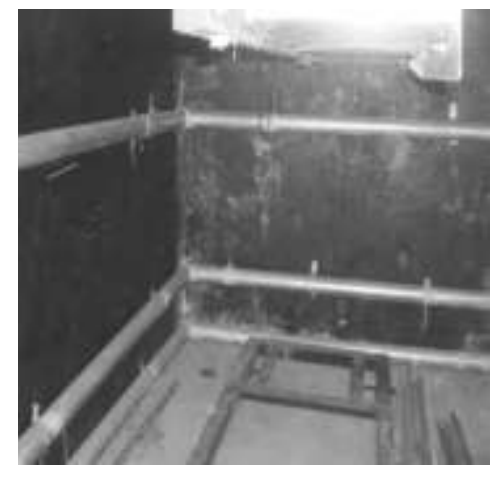

(a)

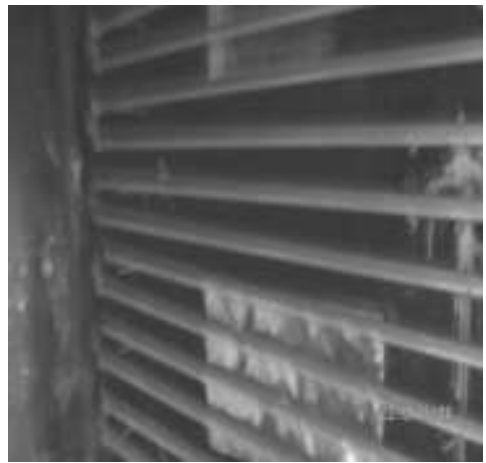

(b)

Figure 2.1: Arrangement of the hot air pipe in the kiln chamber: (a) Previous study; (b) Present study

Rubber wood (Hevea brasiliensis) was used to investigate the timber seasoning performance of the kiln. Dimensions of used sample green timber boards were $100 \mathrm{~cm}$ x $15 \mathrm{~cm}$ x $2.5 \mathrm{~cm}$ (length, width and thickness). Used sticker thickness was $2.5 \mathrm{~cm}$ and $25 \mathrm{ft}^{3}$ of rubber wood was used for the experiment. Kiln run was carried out until timber boards reach to moisture content of $13 \%$ which is the equilibrium moisture content of the environment. At equilibrium moisture content timber neither absorbs nor desorbs water (Desch and Dinwoodle, 1981). Wet-bulb and dry-bulb temperature readings, weight of sample boards, dimensions of sample boards were recorded at regular intervals during the kiln run.

Another kiln run was carried out for a timber species mix. Timber species used other than Rubber wood (Hevea brasiliensis), were Mahogany (Swietenia macrophylla), Lunumidella (Melia dubia), and Albizia (Paraserianthes falcataria). The kiln run was carried out similar to above mentioned kiln run which was done for Rubber wood (Hevea brasiliensis). Selection of sample boards was done according to random sampling.

\subsection{INVESTIGATION OF COST EFFICIENCY OF THE SAWDUST OPERATED KILN}

This kiln in the present study was compared with another two industrially operated kilns in the country for the cost efficiency, using three criteria for rubber wood (Hevea brasiliensis); i.e. Cost of seasoning per unit volume of timber, cost of seasoning per unit volume of timber per unit time and cost - benefit analysis. 
Considered costs were establishment cost of kiln (investment cost), maintenance cost for the kiln, cost for the energy, cost of labour cost of timber input and cost of $\mathrm{CO}_{2}$ emission during kiln operations (if exhaustible energy sources are used).Considered benefits were revenue coming from selling of seasoned timber, cost savings due to use of wood waste, benefit for $\mathrm{CO}_{2}$ emission (global benefit) and building resale value of the kiln chamber at the end of kiln machinery life time. It was assumed that annual discount rate is $10 \%$, annual depreciation rate for buildings is $6 \%$ and timber supply during the concerned period of time is consistent. Under the cost-benefit analysis Net Present Value (NPV) for each kiln was calculated based on this information for 15 years of kiln operation.

The kiln in the present study (UNI) which is situated in University of Sri Jayewardenepura has been originally designed for timber seasoning by dehumidification. However, now it has been connected to a sawdust burner and hot air is the medium of heat transfer. Kiln chamber has a capacity of $50 \mathrm{ft}^{3}$. The other two kilns selected for the comparison was, kiln at State Timber Corporation and kiln at Rowood Lanka (Pvt) Ltd. The kiln located at State Timber Corporation (STC) in Kaldemulla is operated by two steam boilers. One boiler consumes firewood and the other one consumes furnace oil. The kiln chamber has a capacity of $4096 \mathrm{ft}^{3}$.The kiln operated in Rowood Lanka (Pvt) Ltd (RWD) which is situated in Nelundeniya, sawdust is combusted in order to generate steam by a boiler. Generated steam is delivered through a metal pipe in order to exchange heat to the chamber which has a capacity of $920 \mathrm{ft}^{3}$.

\section{RESULTS AND DISCUSSION}

\subsection{PERFORMANCE OF THE KILN}

All three tested sawdust groups (i.e. particles $<1 \mathrm{~mm},>1 \mathrm{~mm}$ and non-sieved sawdust) showed a rapid increase of temperature in water at the initial stage of the experiment. Final temperature of water varied with the sawdust particle size. Wider particles $(>1 \mathrm{~mm})$ gave higher temperature compared with narrower particles $(<1 \mathrm{~mm})$ and mixture of particles had temperature in between those two sawdust particle sizes (Figure 3.1 a).
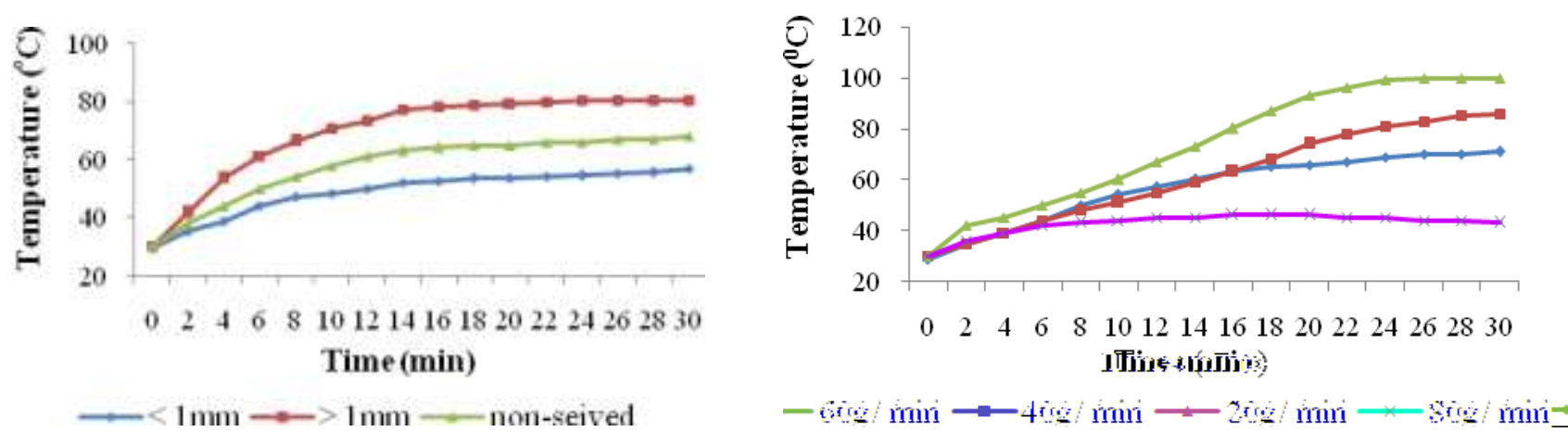

Figure 3.1: Variation of temperature in water mass; (a) against different sawdust particle sizes; (b) against different sawdust feeding rates

Temperature of water also changed with different sawdust feeding rates (Figure $3.1 \mathrm{~b}$ ). Burner was tested for feeding rates of $20 \mathrm{~g} \mathrm{~min}^{-1}, 40 \mathrm{~g} \mathrm{~min}^{-1}, 60 \mathrm{~g} \mathrm{~min}^{-1}$ and $80 \mathrm{~g} \mathrm{~min}^{-1}$, According to results, all four feeding rates showed an increase in temperature at the beginning. Thereafter for 80 $\mathrm{g} \mathrm{min}^{-1}$ rate, temperature decreased with the time. For other three feeding rates, temperature increased and thereafter reached almost to a constant value. 
The bulk density of sawdust is $184 \mathrm{~kg} \mathrm{~m}^{-3}$ (Fungtammasan and Jittrepit, 1993). This density value will get higher if the particle sizes are relatively smaller, due to lack of air spaces between sawdust particles. Lack of inter-particle air spaces reflects the limit of $\mathrm{O}_{2}$ content. However, complete burning of sawdust was observed for all tested sawdust particle sizes. That confirms that density or the $\mathrm{O}_{2}$ content is not the reason for the different performances shown by the burner. Weight of the sawdust particles might be the reason. That is due to the presence of unburned sawdust particles in exhaust gas during the burner was tested for sawdust having particle size less than $1 \mathrm{~mm}$. Due to the force of the air blowing into the combustion chamber of the burner from the feeder unit, some amount of sawdust escape with exhaust gas before being combusted. Due to this loss of sawdust, a considerable amount of heat has been lost. However, for sawdust having larger particle sizes, this loss has been minimum due to their relatively higher particle weight.As a result, particle diameter greater than $1 \mathrm{~mm}$ showed a better performance than that of non-sieved sawdust and sawdust having particle diameter of less than $1 \mathrm{~mm}$. Non-sieved sawdust showed the second best performance due to the presence of both larger and smaller sawdust particles.

For sawdust feeding rate, the best burner performance was observed under the feeding rate of $60 \mathrm{~g}$ of sawdust (having moisture content of $9 \%-15 \%$ ) per minute. This reflects that, the maximum amount of sawdust which can be managed by the burner within a minute is $60 \mathrm{~g}$, subjected to $\mathrm{O}_{2}$ content present in the combustion chamber. Similar to $60 \mathrm{~g} \mathrm{~min}^{-1}$, sawdust feeding rates of $20 \mathrm{~g}$ $\min ^{-1}$ and $40 \mathrm{~g} \mathrm{~min}^{-1}$ also showed a complete combustion. However, when it comes to a feeding rate of $80 \mathrm{~g} \mathrm{~min}^{-1}$, the burner has failed to continue the combustion. This might be due to either insufficient $\mathrm{O}_{2}$ content inside the combustion chamber in order to burn $80 \mathrm{~g}$ of sawdust within a minute or design errors of the burner.

Combustion of sawdust was observed in $1 / 4$ of area out the bottom of the burner. This observation confirms that, burner is not utilizing total area for the combustion. This happens due to poor dispersion of sawdust into the combustion chamber of the burner by its feeding unit. Due to that, sawdust is dumped up on one corner of the combustion chamber of the burner. Those dump of sawdust stations adjacent to the door which is used for lighting up the burner and for removal of ash. Being combustion is taken place adjacent to the door of the combustion chamber; it is observed that a considerable amount of hot exhaust gas is slipped through the door. Due to this design error, approximately $75 \%$ of area of the bottom of the combustion chamber remains unused.

\subsection{SEASONING PERFORMANCE}

The seasoning performance of the sawdust operated kiln was tested mainly for rubber wood. The kiln run took approximately 144 hours to reach $13 \%$ of moisture content from green conditions (over $60 \%$ of moisture content). Under the existed kiln conditions; i.e. according to Senadheera (2009), kiln run for rubber had taken approximately 151 hours. The difference between the two lengths of kiln runs is only 7 hours. In the present study only sawdust was used to generate heat but, in the previous study, an electric heater had been used to initiate the heating which facilitate rapid heating of the chamber initially compared with using only sawdust. During the kiln run, dry bulb reached to a maximum temperature of $42^{\circ} \mathrm{C}$ whereas, wet bulb reached to a maximum temperature of $36^{\circ} \mathrm{C}$. The percentage shrinkage values obtained for tangential and radial directions were $0.66 \%$ and $0.45 \%$ respectively. Thus, tangential shrinkage showed approximately 1.5 fold higher value than that of radial shrinkage.

When dehumidifying system was used for same kiln chamber, it has taken only 62 hours for each kiln run to dry same volume of rubber wood (Ratnayake, 1998). Therefore, it is obvious that, the performance of the sawdust operated kiln is lower than the dehumidifying system. That dehumidifying system has been approximately 2.5 times more efficient than the sawdust operated burner. In respect of drying rates, sawdust operated kiln showed a relatively low drying rates. Average drying rate was found to be $459 \mathrm{~g}$ of water evaporated per hour while dehumidifying system has exhibited an average drying rate of $1290 \mathrm{~g}$ of water per hour. 
When drying rate is expressed as reduction of \% $\mathrm{MC}$ per hour, in respect of present study it ranged $0.04-0.90 \% \mathrm{MC} \mathrm{hr}^{-1}$ and in respect of previous study (Senadheera, 2009) it ranged $0.16-0.60$ $\% \mathrm{MC} \mathrm{hr}{ }^{1}$. Regarding drying efficiency, the overall drying efficiency of the present study was $81.3 \%$ compared to $92.4 \%$ with regards to dehumidifying system (Ratnayake, 1998). When four timber species was seasoning in the sawdust operated kiln, it was observed that Albizia showed the highest drying rate followed by Rubber, Lunumidella and Mahogany.

\subsection{COST COMPARISON AND COST-BENEFIT ANALYSIS}

Results for cost of seasoning per unit volume of timber (rubber wood) and unit time were Rs 429.84 for UNI, Rs 250.98 for STC and Rs 254.31 for RWD. According to results obtained for the comparison, the sequence of kilns for the cost efficiency is UNI $<$ RWD $<$ STC. However, if the cost of $\mathrm{CO}_{2}$ emission is considered (due to use of furnace oil by STC kiln and due to use of electricity derived from fossil fuels), the cost associated with seasoning of one cubic foot will cost Rs 260.90 for STC, Rs 256.60 for RWD and Rs 434.50 for UNI. Thus, ascending order of kilns for cost efficiency shifts to UNI < STC < RWD. The present market value of cubic foot of seasoned rubber wood is approximately Rs. 400. However, the cost of seasoning associated with UNI kiln for one cubic foot of rubber wood is Rs 429 . Thus, there is always a loss of Rs 29 per cubic foot of rubber wood seasoned using UNI kiln. Therefore, UNI kiln is not suitable as an enterprise.

Length of the kiln run is a very important consideration in comparing different kilns. If the time required to dry timber to the desired moisture content is high, inevitably costs associated with energy and labour will be high. Results for cost of seasoning per unit volume of timber and unit time were Rs 3.02 for UNI, Rs 1.81 for STC and Rs 1.19 for RWD. According to results obtained for the comparison, the sequence of kilns for the cost efficiency is UNI $<$ STC $<$ RWD.

At a glance, both comparisons described above reflect a similar result. The result is, the ascending order of kilns for the cost efficiency will be UNI < STC < RWD. However, by investigating the cost proportion (i.e. the ratio between the cost of particular kiln and the cost of kiln which bears the least value), the two comparisons reflects two different results (Table 3.1).

Table 3.1: Cost proportions for cost of seasoning for selected kilns

\begin{tabular}{lcc}
\hline Kiln & \multicolumn{2}{c}{ Comparison } \\
\cline { 2 - 3 } & Cost for unit volume & Cost for unit volume and time \\
\hline UNI & 1.69 & 2.54 \\
STC & 1.02 & 1.53 \\
RWD & 1.00 & 1.00 \\
\hline
\end{tabular}

Regarding the cost of unit volume, both RWD and STC kilns have approximately a similar cost of seasoning. However, if time factor is considered for the comparison, cost of seasoning for STC kiln is almost 1.5 fold higher than that of RWD kiln. When it comes to UNI kiln, its cost of seasoning per unit volume of timber is approximately 1.7 fold higher than that of RWD kiln. However, if time factor is considered that value for UNI kiln rises up to approximately 2.5 fold higher than that of RWD kiln. According to the results obtained, seasoning cost per cubic foot increases in the order of RWD $<$ STC $<$ UNI.

For kiln seasoning of timber, energy cost or the cost associated with heat generation is important as it indirectly affects the length of the kiln run and reflects the degree of heat loss associated with the kiln. Contribution of different costs on the total cost of seasoning varies kiln to kiln (Table 3.2). Despite both UNI and RWD kilns are entirely sawdust operated; their cost of electricity contributes approximately $20 \%$ on the total cost of seasoning while that contribution with respect to STC kiln is only $0.7 \%$. Regarding the energy source used for the generation of heat, it is $3.6 \%$ (sawdust) for UNI kiln, 24.4\% (fuel wood and furnace oil) for STC kiln and 2.6\% (sawdust) for 
RWD kiln. In considering the contribution of total cost of energy on the total cost of seasoning, for UNI, STC and RWD kilns are $26.8 \%, 25.1 \%$ and $21.7 \%$ respectively. Therefore, the sequence of kilns regarding energy cost efficiency is UNI $<$ STC $<$ RWD. A special point to be emphasized is cost of $\mathrm{CO}_{2}$ emission which is shown by STC kiln due to combustion of furnace oil which is a non-renewable energy source. Cost of $\mathrm{CO}_{2}$ emission has been $3.8 \%$ of the total cost of seasoning which is even higher than that of cost of electricity $(0.7 \%)$. This cost is not a cost for the kiln enterprise in fact. However, this cost is a cost to the environment or to the global community.

Regarding STC and RWD kilns, cost of seasoning per unit volume is almost same. For those two kilns, contribution of cost of timber on the total cost of seasoning is approximately $60 \%$. Remaining $40 \%$ of cost is associated with other costs of timber seasoning. However, for UNI kiln, cost of timber contributes only $40 \%$ on the total cost of seasoning whereas other costs contribute $60 \%$. That is the reason for low cost efficiency of UNI kiln.

Table 3.2: Percentage contribution of different costs on total cost of seasoning

\begin{tabular}{lrrr}
\hline Costs $\left(\right.$ Rs yr $\left.^{-1}\right)$ & \multicolumn{3}{c}{ \% Contribution } \\
\cline { 2 - 4 } & UNI & STC & RWD \\
\hline Annualised cost & 1.5 & 2.6 & 1.0 \\
Timber & 36.8 & 61.3 & 62.4 \\
Labour & 31.3 & 7.0 & 13.1 \\
Maintenance & 2.6 & 0.3 & 1.0 \\
Electricity & 23.2 & 0.7 & 19.1 \\
Fuelwood & 0.0 & 10.2 & 0.0 \\
Sawdust & 3.6 & 0.0 & 2.6 \\
Furnace oil & 0.0 & 14.2 & 0.0 \\
CO $_{2}$ emission & 1.1 & 3.8 & 0.9 \\
Total & 100.0 & 100.0 & 100.0 \\
\hline
\end{tabular}

According to cost-benefit analysis, Net Present Values obtained by UNI, STC and RWD kilns were $2.68,104.43$ and 28.84 in Sri Lankan rupees millions respectively. STC kiln has obtained the highest NPV whereas; UNI kiln has obtained the lowest NPV. Thus, according to the cost - benefit analysis, the sequence of benefit generation of kilns will be UNI < RWD < STC. However, based on the results of the cost-benefit analysis STC kiln can be recommended for an enterprise for a long run as STC kiln obtained the highest NPV. Out of selected kilns, STC kiln has the largest chamber capacity. Literature says that, drying cost increases for smaller kilns than the larger kilns (Gjredrum, 2000). Due to higher revenue comes from the higher volume of timber; STC kiln obtained a higher NPV for the concerned 15 years. Though cost of seasoning per unit volume is almost same for both STC and RWD kilns, RWD kiln has obtained a lower NPV for cost benefit analysis due to low chamber capacity with compared to STC kiln. Although, sawdust operated kilns (UNI and RWD) were benefited with savings from use of sawdust and benefit due to use of carbon dioxide neutral fuels, they have failed to compete with STC kiln due to relatively lower chamber capacities and higher cost of electricity. Thus, higher revenue in cost-benefit analysis was mainly influenced by higher chamber capacity of the kiln.

\section{IMPROVEMENTS FOR THE SAWDUST OPERATED KILN (UNI)}

The very first step to be taken in order to develop UNI kiln is to correct the design error of dumping sawdust on one corner of the combustion chamber. This error is due to incorrect orientation of sawdust feeding pipe towards the combustion chamber of the burner. The angle of the pipe should be set to fall sawdust on to the centre of the combustion chamber. That will ensure 
the sawdust combustion using the entire space of the combustion chamber. This correction will help reducing the frequency of sawdust feeding. Reduced frequency of sawdust feeding will increase the temperature of exhaust gas with minimum ash content in the exhaust gas. Frequent feeding of sawdust reduces the temperature of exhaust gas and it increases the release of ash with the exhaust gas. Door of the combustion chamber should also be rotated 90 degrees from the existing position in order to reduce the amount of exhaust gas slips through the door.

The next important design parameter to be improved is to pass the generated heat in to the kiln chamber with a minimum of heat loss. Heat can be exchanged to the kiln chamber by number of ways such as, direct sending of exhaust gas, through a heat exchanger with exhaust gas (existing technology in UNI kiln), through a heat exchanger with hot water or steam etc. The existing technology regarding UNI kiln for heat exchange is, use of hot exhaust gas as the medium of heat exchange. Use of hot air as the heat exchange for kiln seasoning of timber is very rare (Perry and Chilton, 1973). According to the observations obtained in the present study, use of hot air has not been successful for UNI kiln. In order to continue this technology, there should be a very high temperature in exhaust gas with minimum of ash content. Sending exhaust gas directly to the kiln chamber seems to be easy and efficient. However, timber might be discoloured due to presence of ash and other gaseous products in the exhaust gas. Due to discolouration customer preference on seasoned timber might go down.

Hence it is suggested to use steam or hot water as the heat exchange medium for UNI kiln. As water has relatively a higher specific heat capacity; water can absorb a higher fraction of heat generated by the burner and can transfer heat in to the kiln chamber through a heat exchanger pipe system. Since the burner performance is low in the UNI kiln, it is important to capture a higher fraction of heat in order to heat the kiln chamber. Therefore, a boiler unit can be installed to the burner in order to capture heat from the burner and that heat in steam or hot water can be transferred to the kiln chamber through a metal pipe system.

\section{CONCLUSIONS}

Sawdust which has a particle diameter greater than $1 \mathrm{~mm}$ having moisture content of $9 \%-15 \%$ was found to be the most efficient sawdust particle size for the burner and burner shows the highest temperature in exhaust gas, when that sawdust type is fed $60 \mathrm{~g} \mathrm{~min}^{-1}$. Heat production of the burner and heat exchanging technology (use of hot air as the heat exchange medium) adopted for this kiln is not efficient enough to heat up the kiln chamber to higher temperatures. This kiln supports only for fast drying timbers such as Rubber (Hevea brasiliensis) and Allbizia (Paraserianthes falcataria).UNI kiln had the lowest cost efficiency compared with STC and Rowood kilns. Cost efficiency increases in the order of UNI < STC < RWD. However, cost efficiencies of STC and RWD kilns were almost same.STC kiln is the best among the compared kilns for long run of operations. That increases in the order of UNI $<$ RWD $<$ STC.

\section{REFERENCES}

Desch, H.E. and Dinwoodie, J.M. (1981). Timber; Its Structure, Properties and Utilization, $6^{\text {th }}$ edition. pp 155-165

Fungtammasen, B. and Jittrepit, P. (1993). An experimental study on the combustion characteristics of sawdust in a cyclone combuster.

Gjerdrum, P. (2000). Cost efficient timber drying, Proceedings of $2^{\text {nd }}$ Workshop on Quality Drying of Hardwoods, Sopron, Hungary.

Perry, R.H. and Chilton, C.H. (1973). Chemical Engineer's Hand Book, $4^{\text {th }}$ edition. pp 245. 
Ratnayake R.S.S. (1998). Development of drying schedules for rubber and pine timbers for the dehumidification kiln drying, M.Sc. thesis, Department of forestry and environmental science, University of Sri Jayewardenepura, Sri Lanka.

Senadheera, D.K.L.K. (2009). Development of sawdust burner for kiln seasoning of timber, B.Sc. dissertation, Department of forestry and environmental science, University of Sri Jayewardenepura, Sri Lanka.

Weerawansa, P.S. (1997). Evaluation of the saw milling wastage of saw mills in Western Province of Sri Lanka, M.Sc. thesis, Department of forestry and environmental science, University of Sri Jayewardenepura, Sri Lanka. 